\section{Acompanhamento de recém-nascidos de baixo peso pela atenção básica na perspectiva das Equipes de Saúde da Família}

Gabriela dos Santos Buccini

Maria Teresa Cera Sanches 2

Maria Cezira Fantini Nogueira-Martins 3 Andréa Wander Bonamigo 4

\section{Basic care follow-up for underweight newborns from the perspective of Family Health Teams}

1 Núcleo de Apoio à Saúde da Família. APS Santa Marcelina. São Paulo, SP, Brasil.

2,3 Instituto de Saúde. Secretaria Estadual de Saúde de São Paulo. Rua Santo Antônio, $5903^{\circ}$ andar. Bela Vista. São Paulo, SP, Brasil. CEP 01.314-000. E-mail: mtsanches@isaude.sp.gov.br

4 Secretaria Municipal de Saúde de São Paulo. Pirituba, SP, Brasil.

\section{Resumo}

Objetivos: conhecer as percepções e práticas das Equipes de Saúde da Família (ESF) sobre o acompanhamento dos Recém-Nascidos de Baixo Peso (RNBP) pela Atenção Básica (AB).

Método: estudo qualitativo do tipo estudo de caso, no qual se realizaram grupos focais com ESF de uma região periférica do município de São Paulo. O material obtido foi submetido à análise temática para identificação de núcleos de sentido, dos quais emergiram os eixos temáticos centrais.

Resultados: identificaram-se três eixos temáticos centrais: Pré-natal, Acompanhamento longitudinal dos RNBP (clínica ampliada, amamentação e atenção à família) e Educação Permanente. Considerou-se o pré-natal o momento de construção ou fortalecimento do vínculo entre ESF e gestante, entretanto observaram-se entraves para execução de um processo de cuidado integral e longitudinal que perpassa o seguimento dos RNBP. Evidenciaram-se limitações no acompanhamento longitudinal perante a dificuldade das ESF em coordenar e articular a rede de cuidados; executar protocolos e diretrizes nacionais; manejar questões do cotidiano e da dinâmica familiar; estabelecer e efetuar planos terapêuticos longitudinais. Destacou-se, o papel da gestão na articulação de um projeto de educação permanente.

Conclusões: mediante as percepções e práticas das ESF os RNBP e suas famílias ainda não recebem um atendimento integral na $A B$ como proposto pelas diretrizes nacionais de atenção ao bebê de risco.

Palavras-chave Recém-nascido de baixo peso, Atenção primária à saúde, Programa saúde da família 


\section{Introdução}

Dentre as ações prioritárias da Atenção Básica (AB) desenvolvidas pelas Equipes de Saúde da Família (ESF), destaca-se a assistência integral à saúde dos recém-nascidos (RN), que engloba a promoção do aleitamento materno e o acompanhamento do crescimento e desenvolvimento infantil, com especial atenção aos RN de risco, incluindo-se os bebês nascidos com baixo peso e prematuros.1,2 Essas ações visam a redução da mortalidade infantil e promoção de qualidade de vida, considerando o potencial e especificidade de cada criança. ${ }^{2}$

Outro aspecto importante o qual tem merecido destaque refere-se a um atendimento mais humanizado e de melhor qualidade nos programas da saúde da criança. Nesta perspectiva, vários programas têm sido desenvolvidos pelo Ministério da Saúde (MS), entre eles o Programa de Humanização no Pré-natal e Nascimento (PHPN), que propõe humanização e qualificação da assistência como estratégia para a melhoria do acesso, da cobertura e da qualidade do pré-natal, parto e puerpério. Como parte desse programa, aprovou-se também a norma de atenção humanizada ao recém-nascido de baixo peso (RNBP) - Método Canguru. ${ }^{3}$

O Método Canguru (MC) baseia-se no contato pele a pele precoce entre mãe e filho, visando favorecer o vínculo, promover maior participação dos pais no cuidado, além de estimular o aleitamento materno e alta hospitalar precoce. Caracteriza-se pelo desenvolvimento em três etapas interligadas, as duas primeiras compõem a fase hospitalar ( $1^{\mathrm{a}}$ etapa - unidade de terapia intensiva neonatal e $2^{\mathrm{a}}$ etapa alojamento canguru) e são de extrema importância para a sobrevida destes bebês. ${ }^{3}$ Após a alta hospitalar, inicia-se a $3^{\mathrm{a}}$ etapa, que consiste no seguimento ambulatorial específico até que o bebê atinja $2500 \mathrm{~g}$, com orientação e acompanhamento assegurados na unidade hospitalar e, posteriormente, na unidade básica de saúde (UBS) de referência.2-6

A Política Nacional de Atenção Básica e a Agenda de Compromissos para a Saúde Integral da Criança e Redução da Mortalidade Infantil prevêem a articulação entre atenção básica e hospitalar.1,2 Esta rede de cuidados deve garantir a continuidade da assistência à criança com maior risco de morbimortalidade. Para tanto, a comunicação entre os níveis de atenção podem se dar por meio de relatório de atendimento (contra-referência), telefone ou outras alternativas, e caso necessário a captação da criança (busca ativa/visita domiciliar) para que se garanta o acompanhamento na atenção básica assegurando uma visão integral e singular sobre a criança e sua família.1,2

No entanto no caso dos RNBP, muito se precisa avançar para uma efetiva interlocução e integração entre a atenção básica e hospitalar, uma vez que tecer uma rede de cuidados à essa população, garantindo o acesso aos serviços de saúde, a integralidade, a resolubilidade adequada e que promova a equidade depende não só das equipes de saúde, mas também do envolvimento da gestão. 1,2,4,6

Poucos estudos têm sido realizados no intuito de analisar como está se desenvolvendo o acompanhamento ambulatorial dos RNBP na atenção básica ou quão preparados estão as equipes de saúde para recebê-los. ${ }^{4-6}$ Alguns estudos brasileiros foram realizados na atenção especializada, com vistas a avaliar e comparar o crescimento e desenvolvimento dos RNBP7,8 ou estudar os determinantes da amamentação, ${ }^{9}$ porém com foco quantitativo. Já na atenção básica, alguns estudos qualitativos exploraram o tema do acompanhamento dos RNBP e prematuros após a alta hospitalar, enfocando especialmente o seguimento da saúde da criança, ${ }^{4}$ os cuidados domiciliares da enfermagem, 5 e a identificação da rede social e do apoio social das famílias. 6

Diante deste cenário, o presente estudo tem como objetivo conhecer as percepções e as práticas das ESF no acompanhamento longitudinal dos RNBP em uma região periférica do município de São Paulo.

\section{Métodos}

O estudo é um desdobramento da pesquisa sobre os fatores associados à amamentação exclusiva dos RNBP realizada no ano de $2007 \mathrm{em}$ todas as UBS do território de Pirituba e Perus, área situada na periferia norte do município de São Paulo. Essa região caracterizava-se pela alta vulnerabilidade social e pelo alto índice de nascimentos de RNBP no momento do estudo.

Com vistas à compreender como se desenvolve o acompanhamento longitudinal dos RNBP na atenção básica a partir das percepções dos atores que dela participam, nesta pesquisa utilizou-se o enfoque qualitativo. ${ }^{10,11}$ Optou-se pelo estudo de caso, pois permite a análise intensiva de situações e a compreensão de fenômenos sociais complexos que se circunscreve em micro ou macro realidades. ${ }^{12,13}$

A técnica utilizada foi a dos grupos focais, que consiste em entrevistas grupais, em que um moderador conduz a discussão de um pequeno grupo de pessoas em torno de tópicos por ele apresentados, previamente listados em um roteiro. A intenção é 
permitir e facilitar que os participantes expressem opiniões, percepções e sentimentos em relação a questões específicas, possibilitando identificar experiências e necessidades. ${ }^{11,14}$

A amostra foi intencional (não aleatória), correspondendo aos objetivos e propósitos da pesquisa. ${ }^{11,14}$ Optou-se pela seleção da amostra por equipes, pois se buscou compreender não só as percepções e as práticas dos profissionais por categorias, isoladamente, mas também, como esses aspectos se revelam nas equipes.

A população foi composta pelas ESF do território de abrangência da Supervisão Técnica de Saúde de Pirituba e Perus. No momento do estudo, segundo o Sistema de Informações da Atenção Básica (SIAB), existiam 58 ESF e 564 profissionais (52 médicos, 54 enfermeiros, 116 auxiliares de enfermagem e 341 agentes comunitários de saúde ACS) distribuídos em 15 UBS, que atendiam a 208.283 pessoas cadastradas $(37,4 \%$ do total da população desta região).

Considerou-se como critério de elegibilidade, equipes completas (um médico, um enfermeiro, dois auxiliares de enfermagem e cinco ou seis ACS) e que atuavam com os mesmos profissionais há no mínimo seis meses. Do total de 58 ESF do território, foram excluídas 27, por não atenderem ao critério de elegibilidade. Para compor a amostra foi realizado um sorteio entre as 31 ESF que se encontravam completas por ocasião do estudo, considerando-se o número adequado de participantes em cada grupo focal (seis a 15 pessoas). ${ }^{14}$ Ao final do processo, selecionaram-se sete ESF, divididas em dois grupos, de acordo com o território de abrangência: grupo A (território de Pirituba), composto por quatro ESF e o grupo B (território de Perus), com três ESF. Realizaram-se dois grupos focais, com uma sessão em cada grupo e tempo médio de duração de 95 minutos. 11,14

Participaram das entrevistas grupais 28 profissionais de saúde, de diferentes especialidades. As características dos grupos A e B foram homogêneas em relação ao perfil dos profissionais que compunham as ESF participantes, conforme descrição na Tabela 1.

As entrevistas foram gravadas e, posteriormente,

\section{Tabela 1}

Distribuição dos entrevistados segundo características do perfil dos profissionais pertencentes às Equipes de Saúde da Família e grupo de estudo. Supervisão Técnica de Saúde Pirituba/Perus, 2007.

\begin{tabular}{|c|c|c|}
\hline \multirow[t]{2}{*}{ Características } & \multicolumn{2}{|c|}{ Grupos } \\
\hline & A & B \\
\hline \multicolumn{3}{|l|}{ Profissionais da saúde } \\
\hline Médico & 4 & 3 \\
\hline Enfermeiro & 4 & 3 \\
\hline Auxiliar de enfermagem & 4 & 3 \\
\hline Agente Comunitário de Saúde & 4 & 3 \\
\hline \multicolumn{3}{|l|}{ Sexo } \\
\hline Feminino & 14 & 9 \\
\hline Masculino & 2 & 3 \\
\hline \multicolumn{3}{|l|}{ Idade (anos) } \\
\hline $20-30$ & 4 & 4 \\
\hline $31-40$ & 5 & 5 \\
\hline $41-50$ & 6 & 3 \\
\hline $51-60$ & 1 & - \\
\hline \multicolumn{3}{|l|}{ Tempo de atuação no PSF (meses) } \\
\hline 6 a 12 & 3 & 3 \\
\hline 13 a 24 & 6 & 4 \\
\hline 25 a 36 & 2 & 1 \\
\hline Mais de 36 & 5 & 4 \\
\hline \multicolumn{3}{|c|}{ Tempo de atuação na equipe (meses) } \\
\hline 6 a 12 & 4 & 4 \\
\hline 13 а 36 & 10 & 5 \\
\hline Mais de 36 & 2 & 3 \\
\hline Total $(n=28)$ & 16 & 12 \\
\hline
\end{tabular}

PSF = Programa de Saúde da Família. 
transcritas. As transcrições foram lidas por pelo menos duas pessoas diferentes, configurando o que tem sido denominado de triangulação de analistas. 10

Os dados coletados foram sistematizados e analisados conforme a técnica de análise temática. ${ }^{11}$ Foram identificados os núcleos de sentido correspondentes aos temas presentes no discurso dos entrevistados e que denotavam os valores de referência e os modelos de comportamento das equipes estudadas. Dos núcleos de sentido identificados a partir do depoimento dos profissionais emergiram eixos temáticos centrais ${ }^{11}$ que serão aqui apresentados e discutidos.

Este estudo foi aprovado pelo Comitê de Ética em Pesquisa da Secretaria Municipal de Saúde do Município de São Paulo. Todos os participantes leram e assinaram o "Termo de Consentimento Livre e Esclarecido", de acordo com a resolução 196/96 do Conselho Nacional de Saúde.

\section{Resultados e Discussão}

As práticas e percepções dos profisssionais das ESF acerca do acompanhamento longitudinal do RNBP identificadas serão apresentadas por meio de três eixos temáticos emergentes do material, conforme apresentados a seguir.

\section{Pré-natal:uma estratégia de prevenção}

$\mathrm{Na}$ visão dos profissionais, especialmente da área de enfermagem, o pré-natal é um espaço para detecção precoce de intercorrências e realização de ações de prevenção à saúde, inclusive para a prevenção do nascimento de RNBP. Para garantir o acompanhamento das gestantes de risco nas consultas, as ESF elaboram estratégias para o monitoramento do seguimento, conforme se observou no discurso de um profissional médico:

\footnotetext{
Acho que a gente faz um pré-natal bom, melhor possível

[...] Nosso maior problema é a gestante e o pré-natal de alto risco. Se ela não veio direitinho, sabemos o endereço, temos como rastrear isso de uma forma muito melhor. Nós vamos a casa para ver o que está acontecendo. (Médico Grupo A)
}

A questão da não aderência ao pré-natal pode sinalizar uma atuação profissional que esteja desconsiderando a dimensão histórica e psicossocial e dificultando a elaboração de estratégias que promovam a autonomia e responsabilização da gestante por sua saúde.
No estudo de Costa et al.,15 o qual avaliou os cuidados primários à saúde da gestante no contexto da ESF, destacou-se que a assistência pré-natal no Brasil ainda está desarticulada e parcial, com maior ênfase no aspecto curativo, em uma perspectiva "biologizada" e fragmentada das gestantes, atuando meramente através de consultas-procedimento. 15,16 Nesse sentido, estudo sobre a perspectiva das mulheres na avaliação do PHPN, identificou uma dissonância entre as orientações e recomendações realizadas e os reais desejos e necessidades das mulheres, provocando tanto prejuízos ao vínculo com o serviço de saúde, quanto à aderência às orientações recebidas, levando a mulher a traçar para si um outro fluxo de atendimentos. 17

Vale a pena ressaltar o esforço de alguns profissionais no sentido de ampliar o olhar sobre o contexto social e do estilo de vida da gestante, como pode ser constatado no discurso do enfermeiro a seguir:

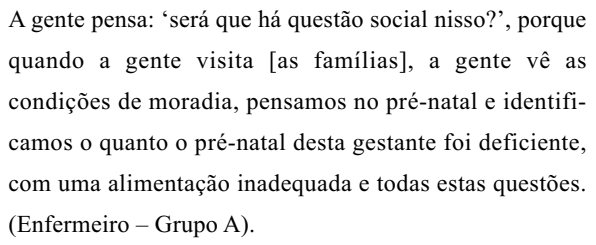

Notou-se que ainda existem dificuldades, por parte das ESF participantes, no manejo das subjetividades intrínsecas aos riscos biológicos identificados e na execução de intervenções longitudinais, que podem estar refletindo na efetividade da assistência prestada pelas ESF.

O PHPN define que nas atividades do acompanhamento pré-natal sejam identificados e monitorados os riscos a que cada gestante está exposta, considerando-se, inclusive, a realidade epidemiológica local, para dar maior ou menor relevância aos fatores de risco. ${ }^{18}$ Contudo, os protocolos de risco e vulnerabilidade estabelecidos no Brasil,18 não dimensionam a complexidade do manejo dos componentes socioambientais e de estilo de vida apontados pelas ESF neste estudo. Somado a esse fato, existe a questão da formação biológica e biomédica dos profissionais de saúde, treinados a identificar riscos e atuar sobre eles. 16,19,20 Percebe-se que apesar de identificados, os riscos nem sempre são abordados de maneira efetiva, gerando intervenções como encaminhamentos para alto risco ou alta complexidade, que podem ser alternativas não resolutivas para os casos mais complexos. $4,6,21$ 
Acompanhamento longitudinal dos RNBP: clínica ampliada, amamentação e família

\section{Clínica ampliada}

Os profissionais relataram que o acompanhamento ambulatorial clínico dos RNBP e/ou prematuros é realizado pelo profissional médico. Destacou-se, inicialmente nos discursos, maior preocupação dos médicos em relação às intercorrências, ao ganho de peso e ao acompanhamento do esquema vacinal. Por outro lado, os enfermeiros mostraram-se preocupados com os cuidados do ambiente e do RNBP, evidenciando a relação direta com a atribuição de cada categoria profissional, como destacado no trecho a seguir:

\footnotetext{
O RNBP perde calor com muita facilidade, então, tem que orientar a mãe para que o bebê esteja bem agasalhado, com o máximo de tempo em contato pele a pele, ter cuidado com as vacinas, fazer um acompanhamento semanal, e observar qualquer tipo de alteração. (Médico Grupo A)
}

Eu visito todas as puérperas, quando tem RNBP eu peço para ir até a unidade para avaliação do médico e para controle de peso. Tem também aquela orientação para o ambiente da família e da casa, porque às vezes a gente chega e a casa está toda fechada, úmida e suja. Aos poucos, nós conversamos e orientamos, explicando que agora tem um bebezinho mais sensível. (Enfermeira Grupo B)

Todos os participantes consideraram o acompanhamento longitudinal e o trabalho com a família, durante o processo de crescimento e desenvolvimento, uma oportunidade de intervir sobre os riscos e reduzir as vulnerabilidades. Constatou-se que dentro deste processo, todas as equipes participantes elegeram o médico como o coordenador do cuidado do RNBP. Contudo, por se tratar de um RN de risco, pode-se observar que os outros membros da equipe se inserem no projeto terapêutico na tentativa de ampliar o olhar clínico e manejar outras questões relacionadas ao contexto familiar e social do RNBP.

Segundo as diretrizes da atenção básica e da saúde da criança, o acompanhamento longitudinal do RNBP deve ser pautado nos pressupostos da clínica ampliada e do projeto terapêutico singular. ${ }^{21} \mathrm{O}$ principal objetivo desta assistência é manter a periodicidade das consultas e visitas domiciliares, de acordo com o fator de risco, para que a intervenção, quando necessária, ocorra precocemente, diminuindo as possibilidades de reinternação.1-6 Para tanto, foram pactuados pelos municípios brasileiros, protocolos e fluxos de atenção a saúde do RN de risco, destacando-se a captação precoce do $\mathrm{RN}$ e o papel de coordenação do cuidado da atenção básica. ${ }^{1,2}$ No município de São Paulo, esses compromissos foram reafirmados por meio da Rede de Proteção à Mãe Paulistana (Decreto Lei No 43.407/2003).

De acordo com as recomendações atuais do Ministério da Saúde, o seguimento dos RNPB, depois que completam $2500 \mathrm{~g}$, passa a ser responsabilidade da atenção básica, na maioria dos municípios. Algumas ESF relataram que buscam materiais e informações para embasar suas condutas profissionais, como mostra um depoimento de um enfermeiro:

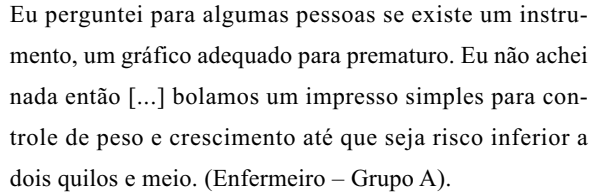

Constatou-se a insegurança da maioria dos profissionais em manejar o acompanhamento longitudinal dos RNBP. Na busca por uma conduta mais responsável e resolutiva estas equipes apóiam-se em instrumentos e parâmetros não oficiais. A constatação desta falta de instrumentalização sugere a necessidade de uma capacitação específica. Segundo Vieira e Mello, ${ }^{4}$ o acompanhamento do RNBP após a alta hospitalar ainda é limitado, tanto no que se refere ao conhecimento da evolução dessas crianças, como das intervenções voltadas às suas peculiaridades e de sua família, percebendo-se uma falha na atenção interdisciplinar após a alta hospitalar. Vale ressaltar que, até o momento, não existe uma proposta definida de capacitação para os profissionais e equipes da Atenção Básica/Saúde da Família a respeito do acompanhamento longitudinal dos RNBP, como o que ocorre para as equipes interdisciplinares das maternidades para a implantação do Método Canguru, desde 2000.3

\section{Amamentação e atenção à família}

Todas as equipes consideraram a prática da amamentação exclusiva para os RNBP como essencial para proteção de sua saúde e prevenção de riscos e morbidades. Neste sentido, destacaram a importância de oferecer maior apoio e reforçar orientações, como relatado pelo ACS:

\footnotetext{
Como a gente frequenta a casa, encontra na rua $[\ldots]$ podemos oferecer apoio como ACS e como amigo [...] nas visitas a gente vai informando como faz com o ambiente, com a família, levando as mensagens da equipe e conver-
} 
sando. Passamos na casa quase todos os dias para ver se o bebê está mamando, se está sugando direitinho... (ACS Grupo A)

Notou-se que a visita domiciliar é utilizada como importante meio de aproximação e vínculo entre as ESF e as famílias, contudo, conforme o relato das equipes participantes, as ações concentram-se em torno de práticas curativas direcionadas aos indivíduos, tornando-se secundárias a produção de autonomia e a corresponsabilização das famílias no cuidado à saúde.

Em consonância com estes achados, outros estudos têm destacado as visitas domiciliares como fonte importante para integrar e dar continuidade as ações das ESF de maneira mais integral e resolutiva.4,5,22 No caso dos RNBP, as visitas domiciliares podem ser fundamentais para execução de intervenções junto à dinâmica familiar visando proteger e promover o aleitamento materno exclusivo. 4,5

O manejo dos mitos relacionado à resistência ao aleitamento materno exclusivo e o pouco ganho de peso foi considerado uma questão marcante quando se trata de RNBP e prematuros, evidenciando-se que esta é uma preocupação da mãe e da família, e uma situação de difícil manejo para as ESF. Perante isso, as ESF percebem no dia-a-dia, maior vulnerabilidade destas mães à introdução precoce de outros alimentos e uso de bicos artificiais (chupetas e mamadeiras), conforme destacado no trecho a seguir:

\footnotetext{
Por mais que orientamos[...] as mães acabam dando o leite artificial para a criança[...]. Tem ainda um pouco de resistência sobre o aleitamento materno exclusivo, principalmente quando se trata de um RNBP, acham que o leite é fraco, que a criança não vai engordar só com o aleitamento materno[...] (Enfermeiro - Grupo B)
}

O manejo das angústias, ansiedades e expectativas da família em relação ao peso do bebê foi um entrave constatado neste estudo. As equipes conseguem detectar a fragilidade das mães dos RNBP, contudo apresentam dificuldades em manejar a situação. Atribuem tal fato ao pouco conhecimento dos parâmetros esperados de ganho de peso para bebês prematuros e RNBP amamentados exclusivamente.

Evidências da literatura indicam que os RNBP amamentados exclusivamente ao peito podem ter um crescimento diferenciado em relação aos que recebem aleitamento misto, da mesma maneira quando são comparados a bebês a termo com peso adequado ao nascer, os quais geralmente ganham mais peso, o que não significa problemas com o crescimento da criança. $7-9$

Outro tema debatido pela maioria dos participantes, também relacionado ao problema do baixo ganho de peso foi o choro "excessivo". As equipes relataram fatores sociais e culturais da família e da comunidade que interferem no manejo desse aspecto e que pode levar ao desmame precoce. O relato abaixo de um enfermeiro ilustra os aspectos que envolvem o ganho de peso e o choro excessivo:

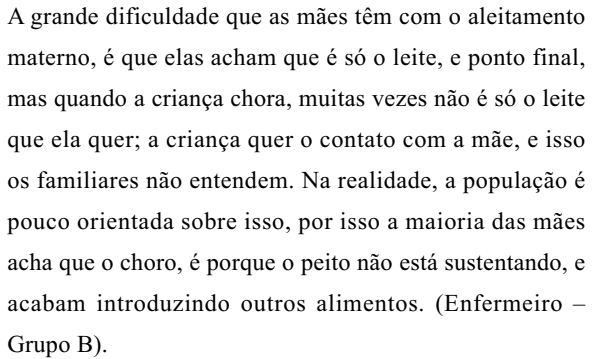

Observou-se também neste estudo que alguns profissionais apontaram para a necessidade de atribuir outros significados ao choro do RNBP e orientar a família sobre outras formas de cuidar e acalmar o bebê. Consideraram também que as famílias são pouco orientadas sobre esses aspectos.

Estudos sobre representações maternas acerca da amamentação de RNBP e prematuros indicaram que para a maioria das mulheres a experiência da amamentação é um processo desgastante, permeado de dificuldades, incertezas, ansiedades e culpa, face às inúmeras variáveis estressantes a que foram expostas (tanto na vivência hospitalar como na dinâmica familiar). Auxiliar a família na compreensão das várias intenções que o choro do bebê pode expressar, como fome, desconforto e dor ou pela necessidade de contato físico e atenção pode favorecer a segurança da mãe na amamentação.9,23,24

Um bebê que chora muito pode perturbar o relacionamento entre ele e sua mãe, e ainda, causar tensão emocional entre os membros da família. Essa situação foi destacada pelas ESF, visto que na população adscrita é comum, devido a questões socioeconômicas, a mãe e seu bebê continuarem a viver com sua família de origem.

Dentre os membros que compõem a família, as ESF destacaram a avó como a pessoa que influencia as atitudes e decisões da puérpera e por isso inclui-la nas orientações e intervenções do pré-natal, puerpério e seguimento longitudinal do RNBP pode ser favorável:

Quando fomos fazer a visita com a puérpera que estava indo no hospital para amamentar[...] sabíamos que 
teríamos que trabalhar um pouco com a avó [...] A avó só ficava desestimulando ela, então o restante da visita domiciliar foi mais focado na orientação da avó. (Enfermeiro Grupo A)

Segundo Silva e Salomão 25 e Teixeira et al.,26 os suportes socioemocionais oferecidos pelas avós podem ser significativos para a mãe e seu bebê, uma vez que ela é a pessoa de referência da mulher, pela experiência acumulada neste processo.

Outro membro importante da família emergido nas narrativas de todos os participantes foi o pai, conforme relato de um enfermeiro:

Incluir o pai é muito legal, todas as pessoas, mas acho que o pai é muito legal; você percebe que quando o pai vem na consulta junto, a mãe se sente mais acolhida, ela se sente muito melhor, muito mais realizada, sente e passa isso pro filho..." (Enfermeiro - Grupo A)

Para os entrevistados, a presença do pai no processo de gestação/pré-natal/puerpério parece contribuir para que ele se sinta parte integrante do mesmo exercendo influência na confiança da puérpera, especialmente se o bebê necessitar de cuidados especiais, como é o caso do bebê prematuro e/ou de baixo peso ao nascer.

Cauduro e Motta27 destacaram que o envolvimento e a participação ativa do homem nas atividades educativas no processo de gestação/puerpério podem propiciar uma transição mais suave para a paternidade. E acrescentam que isso facilita sua inclusão após o nascimento no apoio à mulher, na divisão de tarefas domésticas e nos cuidados ao bebê.

Vale a pena destacar que nos dois grupos focais deste estudo, apesar de as ESF concordarem unanimemente com a importância de envolver toda a família nos cuidados a este novo ser (o RNBP), fizeram silêncio frente à colocação do tema. Somente após várias intervenções da moderadora, as equipes relataram algumas ações que realizavam (ou que poderiam realizar) junto à família, assinalando as dificuldades com que se deparam para concretizar esse trabalho. O silêncio inicial dos grupos frente a esta temática aponta para um aspecto provavelmente pouco considerado, tanto nas práticas como nas capacitações. Parece revelar que, apesar de saberem da importância do trabalho envolvendo toda a família e sobre o manejo da amamentação, não sabem ou não se sentem seguros para manejá-la.

Vieira e Mello4 apontam que a forma como atualmente a equipe de saúde realiza a construção do cuidado junto às famílias, gera uma relação baseada no saber técnico e não na horizontalidade do diálogo, promovendo vínculos frágeis. Segundo as autoras, o acolhimento da criança/família nos serviços públicos de saúde ainda ocorre de maneira fragmentada propiciando insegurança nas famílias, insatisfação e a não efetividade no seguimento da criança. ${ }^{4}$

Para que o suporte da $\mathrm{AB}$ e das ESF seja efetivo faz-se necessário a avaliação da unidade familiar, do apoio social e da rede social que os RNBP e suas famílias poderão acessar para o enfrentamento das situações de vulnerabilidade. ${ }^{6}$ Vale destacar que o apoio social difere da rede social. Apoio social é um processo de interação entre as pessoas que estabelecem vínculos de amizade, apoio material e emocional (dimensão pessoal), enquanto rede social são instituições relacionadas à família tais como sistema de saúde, organizações religiosas, escolas e a vizinhança (dimensão institucional). 6

Assim, o conhecimento desses aspectos pode ser fundamental para o fortalecimento do vínculo entre as ESF e a família além de favorecer um cuidado integral e mais resolutivo. 4,6

\section{Educação permanente: estratégia para qualificar o acompanhamento longitudinal dos RNBP}

De acordo com a análise anterior, referente à falta de uma proposta definida de capacitação para esses profissionais a respeito do seguimento dessa população de risco, como alternativa de reflexão e instrumentalização teórico-prática, emergiu do discurso das equipes, o tema Educação Permanente em Saúde (EPS) e discutiu-se com as ESF como este processo poderia ocorrer dentro das equipes.

As ESF afirmaram que no cotidiano do serviço, mediante os processos de trabalho estabelecidos, os princípios do Sistema Único de Saúde, a discussão e a construção do conhecimento em equipe não são priorizados, mesmo quando se trata de acompanhamentos complexos como o do bebê de risco, conforme o destacado por um enfermeiro:

[...] o que deixamos um pouquinho é a parte técnica, estudo de casos, este é um dos objetivos que deixamos para trás, estamos muito atrás de "apagar incêndio" ainda. Assim deixamos esta parte técnica do conhecimento, o meu conhecimento quanto enfermeiro, o conhecimento dele enquanto médico, do ACS. Então não estamos conseguindo isso, não conseguimos evoluir. (Enfermeiro - Grupo A).

Constatou-se que as ESF priorizam em seu processo de trabalho, pela rotina do cotidiano, 
questões emergenciais e pontuais, colocando em segundo plano os princípios da atenção básica, humanização e a longitudinalidade do cuidado. No acompanhamento do RNBP a desconsideração de tais princípios pode afetar a qualidade da assistência prestada pela ESF.

Para as ESF participantes as possibilidades de viabilizar a educação permanente resumem-se à realização de reuniões pontuais para discussão e troca de informações sobre temas e experiências vivenciados entre os membros das equipes. Destacaram que mesmo para realização dessas reuniões existem diferentes barreiras operacionais e institucionais.

Estudos e diretrizes da atenção básica destacam que o processo de educação permanente pressupõe que aconteça uma aprendizagem significativa (que promove e produz sentidos) e propõe que a transformação das práticas dos profissionais e das equipes se baseie na reflexão crítica destes sobre sua própria atuação prática, em seus territórios.1,19,20,28 As demandas para capacitação devem partir, prioritariamente, de problemas do cotidiano do trabalho com a comunidade, referente à necessidade de prestar ações e serviços relevantes e de qualidade, garantindo aplicabilidade e a relevância dos conteúdos e tecnologias abordadas e estabelecidas nos cursos. $1,20,28,29$

De acordo com experiências divulgadas na tentativa de buscar novos caminhos para viabilizar o processo de EPS para as ESF, a realização de capacitações sequenciais, tem sido apontada como uma estratégia. 30 Estas podem ocorrer com toda equipe e também integrar momentos específicos, em que se pode trabalhar a necessidade de cada categoria profissional. Além disso, a realização de encontros (mensais ou trimestrais) entre as ESF de uma mesma região foi sugerida, como espaço importante de trocas de experiências e busca coletiva de soluções. ${ }^{29,30}$

Outro aspecto identificado pelas ESF referiu-se à participação da gestão como determinante para mudar as práticas de saúde. Contudo a maioria dos profissionais, independentemente da especialidade, destacou que os gestores privilegiam a cobrança de produção e metas, como pode ser observado no discurso de um médico:

Há um tempo atrás todo mundo tinha seu tempo de estudar, eu acho importante voltar a pensar que isso é importante porque as informações mudam todos os dias
[...]Apesar das cobranças por número, a gente tem que ter uma educação continuada. (Médico - Grupo A).

Verificou-se que, na visão das ESF, os gestores têm pouco interesse em estimular os profissionais a participar ou desenvolver algum projeto de educação permanente em saúde.

A EPS é um processo educativo aplicado ao trabalho, apresentando, entre seus objetivos, o favorecimento de mudanças nas relações, nos processos de trabalho, nos atos de saúde e nas pessoas, além de uma melhor articulação para dentro e para fora das instituições. ${ }^{26,29}$ Para tanto, a gestão deve ser articuladora e promotora de mudanças, estabelecendo espaços de diálogo, negociação, identificando necessidades e construindo estratégias para que a educação permanente se concretize. 29

\section{Considerações finais}

Os resultados mostraram que, de acordo com as percepções e práticas das ESF, os RNBP e suas famílias ainda não recebem um atendimento diferenciado, que leve em conta suas particularidades, conforme a indicação dos programas oficiais de atenção ao bebê de risco.

Revelou-se a complexidade do trabalho na atenção básica, principalmente na assistência de uma população de risco. Salientou-se o pouco conhecimento das necessidades de saúde deste grupo por parte das ESF, a importância de uma assistência pautada na longitudinalidade na integralidade e a ampliação da humanização em saúde e do olhar sobre as dificuldades e potencialidades da unidade familiar, considerando a escuta qualificada.

Foi desvelada a necessidade da formação de profissionais com capacidade de reflexão crítica sobre sua prática e o território em que atuam, capazes de integrar diferentes conhecimentos para o planejamento das ações em saúde, mostrando o papel do gestor como articulador do processo de educação permanente nesta área.

\section{Agradecimentos}

Agradecemos à colaboração do Instituto de Saúde da Secretaria Estadual de Saúde de São Paulo pelo apoio material e institucional. À Supervisão Técnica de Saúde de Pirituba/Perus pela parceria e colaboração. 


\section{Referências}

1. Brasil. Ministério da Saúde. Secretaria de Atenção á Saúde. Departamento de Atenção Básica. Portaria no 648/GM, 28 de Março de 2006. Política Nacional de Atenção Básica.

2. Brasil. Ministério da Saúde. Departamento de Ações Programáticas Estratégicas. Agenda de compromissos para a saúde integral da criança e redução da mortalidade infantil. Brasília, DF; 2004. [acesso em 5 fev 2011]. Disponível em: http://bvsms.saude.gov.br/bvs/ publicacoes/agenda_compro_crianca.pdf

3. Brasil. Ministério da Saúde. Secretaria de Atenção à Saúde. Área de Saúde da Criança. Atenção humanizada ao recém nascido de baixo peso: Método Canguru. Brasília, DF; 2009. [acesso em 5 fev 2011]. Disponível em: http://portal. saude.gov.br/portal/arquivos/pdf/manual_canguru.pdf

4. Vieira CS, Mello DF. O seguimento da saúde da criança pré-termo e de baixo peso egressa da terapia intensiva neonatal. Texto \& Contexto Enferm. 2009; 18: 74-82.

5. Mello DF, Rocha SMM, Scochi CGS, Lima RAG. O Cuidado da enfermagem no seguimento de crianças prétermo e de baixo peso ao nascer. Rev Bras Cresc Desenv Hum. 2000; 10: 49-60.

6. Vieira CS, Mello DF, Oliveira BRG, Furtado MCC. Rede e apoio social familiar no seguimento do recém-nascido prétermo e baixo peso ao nascer. Rev Eletr Enf. 2010; 12: 119

7. Penalva O, Schwartzan JS. Estudo descritivo do perfil clínico-nutricional e do seguimento ambulatorial de recémnascidos prematuros atendidos no Programa Método MãeCanguru. J Pediatr (Rio J). 2006; 82: 33-9.

8. Charpak N, Ruiz-Peláez JG, Figueiroa ZC, Charpak Y. A randomized, controlled trial of kangaroo mother care: results of follow-up at 1 year of corrected age. Pediatrics. 2001; 108: 1072-9.

9. Sanches MTC. Fatores associados à amamentação exclusiva de recém-nascidos de baixo peso ao nascer, integrantes do Método Mãe-Canguru [tese]. São Paulo: Faculdade de Saúde Pública da Universidade de São Paulo; 2005.

10. Turato ER. Métodos qualitativos e quantitativos na área da saúde: definições, diferenças e seus objetos de pesquisa. Rev Saúde Pública. 2005; 39: 507-14

11. Nogueira-Martins MCF, Bógus CM. Considerações sobre a metodologia qualitativa como recurso para o estudo das ações de humanização em saúde. Saúde Soc. 2004; 13: 4457

12. Yin RK. Estudo de caso: planejamento e métodos. Tradução de Daniel Grassi. 3 ed. Porto Alegre: Bookman; 2005.

13. Martins GA. Estudo de caso: uma estratégia de pesquisa. 2 ed. São Paulo: Atlas; 2008.

14. Westphal MF, Bógus CM, Faria MM. Grupos focais: experiências precursoras em programas educativos em saúde no Brasil. Bol Oficina Sanit Panam. 1996; 120: 472-82.

15. Costa GD, Cotta RMM, Reis JR, Siqueira-Batista R, Gomes AP, Franceschini SCC. Avaliação do cuidado à saúde da gestante no contexto do Programa Saúde da Família. Ciênc Saúde Coletiva. 2009; 14 (Supl. 1): 1347-57.

16. Ayres JRCM, Calazans GJ, Saletti Filho HC, França-Júnior
I. Risco, vulnerabilidade e práticas de prevenção e promoção da saúde. In: Campos GWS et al. (org). Tratado de Saúde Coletiva. São Paulo/Rio de Janeiro: Hucitec/Fiocruz; 2006. p. 375-417.

17. Almeida I, CAL Tanaka OY. Perspectiva das mulheres na avaliação do Programa de Humanização do Pré-Natal e Nascimento. Rev Saúde Pública. 2009; 43 : 98-104.

18. Brasil. Ministério da Saúde. Secretaria de Atenção à Saúde. Departamento de Ações Programáticas Estratégicas. Prénatal e puerpério atenção qualificada e humanizada. Brasília, DF; 2006. [acesso em 5 fev 2011]. Disponível em: http://portal.saude.gov.br/portal/arquivos/pdf/manual_puerperio_2006.pdf

19. Campos FE, Belisário SA. O Programa de Saúde da Família e os desafios para a formação profissional e a educação continuada. Interface - Comunic Saúde Educ. 2001; 5: 133 42.

20. Buccini GS, Martins MCF, Sanches MTC. O processo de educação permanente em saúde: percepção de equipes de saúde da família. Boletim Instituto de Saúde 2009; 48: 514.

21. Brasil. Ministério da Saúde. Secretaria de Atenção à Saúde. Núcleo Técnico da Política Nacional de Humanização. Clínica ampliada, equipe de referência e projeto terapêutico singular. 2 ed. Brasília, DF; 2007.

22. Giacomozzi CM, Lacerda MR. A prática da assistência domiciliar dos profissionais da estratégia de saúde da família. Texto \& Contexto Enferm. 2006; 15: 645-53.

23. Javorski M. As representações sociais do aleitamento materno para mães de prematuros em unidade de cuidado canguru. Rev Lat-am Enferm. 2004; 12: 890-8.

24. Vasconcelos MGL, Leite AM, Scochi CGS. Significados atribuídos à vivência materna como acompanhante do recém-nascido pré-termo e de baixo peso. Rev Bras Saúde Matern Infant. 2006; 6: 47-57.

25. Silva DV, Salomão NMR. A maternidade na perspectiva de mães adolescentes e avós maternas dos bebês. Estud Psicol (Natal). 2003; 8: 135-45.

26. Teixeira MA, Nitshke RG, De Gasperi P, Sieldler MJ. Significado de avós sobre a prática do aleitamento materno no cotidiano familiar: a cultura do querer-poder amamentar. Texto \& Contexto Enferm. 2006; 15: 98-106.

27. Cauduro LS, Motta MGC. Pai adolescente: percepções de cuidado com o bebê. Rev HCPA, Porto Alegre. 2007; 27 : 10-5

28. Ceccim RB, Feuerwerker LCM. O quadrilátero da formação para a área da saúde: ensino, gestão, atenção e controle social. Physis (Rio J.). 2004; 14: 41-65.

29. Carotta F, Kawamura D, Salazar J. Educação permanente em saúde: uma estratégia de gestão para pensar, refletir e construir práticas educativas e processos de trabalho. Saúde Soc. 2009; 18 (Supl.1): 48-51.

30. Bernadino MTSM, Conversani DTN, Bógus CM, Feliciano AB. Consensos e divergências: a capacitação profissional das equipes de saúde da família no município de São Carlos. Trab Educ Saúde. 2005; 3: 75-89.

Recebido em 1 de fevereiro de 2010

Versão final apresentada em 12 de maio de 2011

Aprovado em 31 de maio de 2011 